\title{
Research Article \\ Kinetic Study and Thermal Decomposition Behavior of Lignite Coal
}

\author{
Mehran Heydari, Moshfiqur Rahman, and Rajender Gupta \\ Department of Chemical and Materials Engineering, University of Alberta, Edmonton, AB, Canada T6G 2V4 \\ Correspondence should be addressed to Rajender Gupta; rajender.gupta@ualberta.ca
}

Received 5 December 2014; Accepted 16 April 2015

Academic Editor: Deepak Kunzru

Copyright ( 2015 Mehran Heydari et al. This is an open access article distributed under the Creative Commons Attribution License, which permits unrestricted use, distribution, and reproduction in any medium, provided the original work is properly cited.

\begin{abstract}
A thermogravimetric analyzer was employed to investigate the thermal behavior and extract the kinetic parameters of Canadian lignite coal. The pyrolysis experiments were conducted in temperatures ranging from $298 \mathrm{~K}$ to $1173 \mathrm{~K}$ under inert atmosphere utilizing six different heating rates of $1,6,9,12,15$, and $18 \mathrm{~K} \mathrm{~min}^{-1}$, respectively. There are different techniques for analyzing the kinetics of solid-state reactions that can generally be classified into two categories: model-fitting and model-free methods. Historically, model-fitting methods are broadly used in solid-state kinetics and show an excellent fit to the experimental data but produce uncertain kinetic parameters especially for nonisothermal conditions. In this work, different model-free techniques such as the Kissinger method and the isoconversional methods of Ozawa, Kissinger-Akahira-Sunose, and Friedman are employed and compared in order to analyze nonisothermal kinetic data and investigate thermal behavior of a lignite coal. Experimental results showed that the activation energy values obtained by the isoconversional methods were in good agreement, but Friedman method was considered to be the best among the model-free methods to evaluate kinetic parameters for solid-state reactions. These results can provide useful information to predict kinetic model of coal pyrolysis and optimization of the process conditions.
\end{abstract}

\section{Introduction}

During the past few decades, petroleum has been the main source of liquid fuels. On one hand, petroleum reserves are declining; on the other hand, coal reserve is the most abundant fossil fuel known in the world [1]. Coal is a source of fuel for more than half of the world's power plants for electricity generation. Coal and coal-derived fuels have been used in residential, commercial, and industrial applications. The amount of coal deposits estimated worldwide is approximately ten times larger than that for the other carbonaceous resources. The availability of coal resources was a main contributor to the economic growth of many countries such as the US, China, India, and Australia [2]. Coal appears to hold the most promise of all the possible alternatives for short-term development to meet the national requirements of energy. Coal and coal products play a major role in fulfilling the energy demands of our society [3]. Direct liquefaction, indirect liquefaction, and gasification are examples of existing processes for coal conversion into energy products. Therefore, coal is of significant industrial and economic importance, both as an energy source and as an industrial feedstock [4]. In large-scale processes of coal conversion to valuable products through thermal treatment, determination of the kinetic parameters in the decomposition stage is one of the key problems. Many unresolved problems face a designer of coal combustors and gasifiers, including the complex physical and chemical behavior of coal and the uncertainty regarding the kinetics of the chemical reactions during thermal decomposition [5]. The design of processes for pulverized coal requires that the various stages occurring during the thermal decomposition be understood in order to provide optimum operating conditions. This greater emphasis on more efficient utilization of coal combined with its chemical complexity raises the need for a better understanding of the pyrolysis process. Pyrolysis is the method for obtaining liquid from coal by rejecting carbon and thereby increasing the hydrogen-to-carbon ratio of raw coal. Pyrolysis takes place as coal is treated at elevated temperatures in the absence of oxygen and during this 
pyrolysis a series of reactions occurs. This is done in the absence of oxygen, so that undesirable combustion reactions cannot take place [6]. The main products of pyrolysis are gas, tar, and char. The products of pyrolysis, that is, the amount and the composition of volatile material, depend primarily on the coal type, reaction temperature, pressure, heating rate, residence time, and particle size.

The heating rate can affect the behavior of the conversion curve. The increase of heating rates results in slight changes in the conversion curve and maximum decomposition rate towards higher temperatures [7]. Pyrolysis kinetics of coal is important because it is the initial step of main coal conversion processes such as liquefaction, gasification, and combustion in which coal particles undergo major physical and chemical transformations. For a better understanding of pyrolysis, several researchers investigated thermal decomposition of coal by thermogravimetric analysis (TGA). As coal has been used as a fuel since the beginning of industrial development, it has been among the earliest materials to be subjected to thermal analysis.

To investigate the kinetics of the decomposition process, TGA is often used. In TGA, the weight change of the sample is observed as it is heated, usually at a constant heating rate under a controlled atmosphere such as nitrogen, air, or other gases. The record of weight loss with respect to the time or temperature is termed a thermogravimetric (TG) thermogram. When the rate of weight loss (the first derivative with respect to time) is recorded as a function of time or temperature, it is called a differential thermogravimetric (DTG) thermogram. The DTG has been used to study the kinetics of thermal decomposition reactions of a variety of solids, including coal. Much of this work is based on the assumption that thermal decomposition is describable by an overall firstorder reaction and follows the Arrhenius-type equation. The kinetics of the thermal behavior of a material can be determined by the application of a kinetic model to the rates of mass degradation. The main advantages of TGA for the study of coal pyrolysis are simplicity in implementation and utilization and good repeatability [8]. A large number of studies have reported on thermogravimetric and differential thermal analysis in an attempt to explain kinetics of thermal decomposition of coal and to obtain qualitative information on coal pyrolysis. The literature reviews on these subjects regarding thermal analysis are present from Howard [9], Lawson [10], Anthony and Howard [11], Hathi [12], and Khawam [13]. The main differences in the thermobalances used for the studies of Honda (1915), Guichard (1926), Vallet (1932), Rigollet (1934), Dubois (1935), Longechambon (1936), and Jouin (1947) were mentioned by Hathi [12] and Khawam [13]. These thermobalances recorded mass versus temperature or time. Van Heerdan and Huntjens studied the rates of decomposition of Dutch coals on a thermobalance that recorded mass loss data continuously over the temperature range $200-550^{\circ} \mathrm{C}$. A mathematical equation in the form of the Arrhenius equation was considered to explain the rate of coal decomposition. They concluded that the decomposition process is first order with regard to the fraction of unreacted coal. They observed that initial devolatilization is fast removal of moisture and oxides of carbon, the middle devolatilization is slow and contains the removal of the major volatile matter from coal, and the final devolatilization is a slow process for liberating the gas from residuals [12]. Scaccia et al. investigated the pyrolysis of low-rank Sulcis coal by thermogravimetric techniques (TG/DTG) in the temperature range ambient to $1000^{\circ} \mathrm{C}$ at three different heating rates. From thermogravimetric results it was established that coal pyrolysis involved three main stages: water evaporation; devolatilization of thermally labile and more stable volatiles; and char formation [14].

The knowledge of kinetic parameters is essential for modeling the reactor and optimization of the process conditions. There are various methods for evaluating kinetic parameters from nonisothermal thermogravimetric analysis (TGA) and the most common of them can be classified into two major types: model-fitting and model-free [14-17]. In the model-fitting method, different models are fit to the experimental data and the model giving the best statistical fit is selected as the model from which the activation energy $\left(E_{a}\right)$ and frequency factor $(A)$ are evaluated. Historically, model-fitting methods were broadly used because of their ability to directly calculate the kinetic parameters from the thermogravimetric analysis results. However, these methods have several drawbacks, the most important one being their inability to uniquely select the appropriate reaction model [13]. Furthermore, comparing the results of these models in the literature can be difficult especially for nonisothermal data since a wide range of kinetic parameters have been determined for the coal pyrolysis process. This led to the decline of these methods in favor of isoconversional (model-free) methods which can estimate the activation energy without evaluating the reaction model [13]. The greatest advantages of this model are its simplicity and avoidance of errors related to selecting specific reaction models. Isoconversional method is called model-free method because of its ability to determine the activation energy for different constant extents of conversion without considering any particular form of the reaction model. These methods require several kinetic curves to perform the analysis and thus are sometimes called multicurve methods [18]. These methods can calculate the activation energy at different heating rates on the same value of conversion. The terms "model-free" and "isoconversional" are sometimes used interchangeably; however, not all modelfree methods are isoconversional. For example, the Kissinger method is a model-free method but is not isoconversional because it does not calculate activation energy at different constant extents of conversion but instead assumes constant activation energy [13].

Isoconversional methods are helpful tools for the analysis of solid-state kinetics. Theoretically, they include many benefits and applications. However, practically, they have some disadvantages especially regarding reproducibility when performing a series of runs at different heating rates in which their fluctuation may enhance experimental errors. Thus, for nonisothermal experiments, each run must be conducted under the same experimental conditions (sample weight, purge gas rate, and sample size), so the only variable is the heating rate. In order to obtain accurate results with high resolution curves low ranges of heating rates can be considered for the experiments. 
Numerous recent studies on the TGA pyrolysis of coal [19-21] and coal-biomass blends [22-24] are available in the literature and most of them are based on model-fitting techniques. There are a few reports relating to thermal decomposition behavior of coal based on model-free techniques [14]. Moreover, most of the previous studies have been performed on coal-biomass blends in order to determine the kinetics of copyrolysis of coal and biomass mixtures. To the best of our knowledge, there is very little information regarding pyrolysis of coal itself based on model-free methods.

The aim of the present work is to study the pyrolysis kinetics of Canadian lignite coal by means of thermogravimetric analysis (TGA) within the temperature range of 298$1173 \mathrm{~K}$ at different heating rates under nitrogen atmosphere. The effect of the heating rate on decomposition will also be studied. In this study, different model-free methods such as the Kissinger and the isoconversional methods of Ozawa, Kissinger-Akahira-Sunose, and Friedman are employed and compared in order to analyze nonisothermal kinetic data and investigate thermal behavior of a Canadian lignite coal. The kinetic parameters of the coal decomposition process will also be determined. These results may provide helpful information for pyrolysis researchers to predict a kinetic model of coal pyrolysis and optimization of the process conditions.

\section{Materials and Methods}

2.1. Sample Preparation. It is estimated that approximately half of the coal resources of the world are low-rank coal, such as lignite and subbituminous coal [25]. Lignite coal is abundant in Canada and plays an important role in energy production. It was thus chosen as the experimental sample in the present study. Canadian lignite coal was obtained from Poplar River Mine located in southern Saskatchewan, Canada. The bulk coal sample was crushed by means of a jaw crusher and ground in a ball mill and blended to homogenize the coal and reduce the particle size between 106 and $150 \mu \mathrm{m}$. The coal sample was received wet with $32 \%$ moisture content and was dried in vacuum oven at $80^{\circ} \mathrm{C}$ for $8 \mathrm{~h}$ until a moisture content of $12 \%$ was achieved. The sample was submitted to both proximate analysis according to the ASTM D7582 by Macro Thermogravimetric Analyzer and ultimate analysis according to ASTM D3176 in Elemental Vario MICRO Cube. The results of the proximate and ultimate analysis (CHNS) as well as higher heating value of the sample used are presented in Table 1. Higher heating value of coal was also calculated with Channiwala and Parikh formula [26]:

$$
\begin{aligned}
\mathrm{HHV}= & 0.3491 \mathrm{C}+1.1783 \mathrm{H}+0.1005 \mathrm{~S}-0.1034 \mathrm{O} \\
& -0.0151 \mathrm{~N}-0.0211 \mathrm{~A}(\mathrm{MJ} / \mathrm{kg}),
\end{aligned}
$$

where $\mathrm{C}, \mathrm{H}, \mathrm{S}, \mathrm{O}, \mathrm{N}$, and $\mathrm{A}$ are the mass fractions of carbon, hydrogen, sulfur, oxygen, nitrogen, and ash, respectively.

2.2. Experimental Method. The TGA experiments were performed using a thermogravimetric analyzer, TGA-SDT Q600, at the coal research center of University of Alberta. About $10 \mathrm{mg}$ of fine coal particle size between 106 and
TABLE 1: Characteristics of the coal sample.

\begin{tabular}{lccc}
\hline Proximate analysis (wt.\%) & \multicolumn{3}{c}{ Ultimate analysis (wt.\%, daf) } \\
\hline Moisture & 12.78 & $\mathrm{C}$ & 44.63 \\
Volatile matter & 41.24 & $\mathrm{H}$ & 4.68 \\
Ash & 19.83 & $\mathrm{~N}$ & 0.66 \\
Fixed carbon & 26.15 & $\mathrm{~S}$ & 0.57 \\
& & $\mathrm{O}^{*}$ & 49.46 \\
& & $\mathrm{HHV}(\mathrm{MJ} / \mathrm{kg})$ & 16.02 \\
\hline
\end{tabular}

daf $=$ dry and ash-free basis. ${ }^{*}$ Obtained by difference.

$150 \mu \mathrm{m}$ was placed in a small Alumina crucible for each run and heated from $298 \mathrm{~K}$ to the maximum temperature of $1173 \mathrm{~K}$ at six different heating rates of $1,6,9,12,15$, and $18 \mathrm{~K} \mathrm{~min}^{-1}$, respectively, under nitrogen atmosphere with a flow rate of $100 \mathrm{~mL} / \mathrm{min}$. During the heating, variation of the weight loss and its derivative with respect to the time and temperature was collected automatically by the instrument and determined through the TA universal analysis software. The experiments were repeated under identical conditions to check the reproducibility of the results.

2.3. Kinetic Analysis. There are a number of approaches for modelling the complex pyrolysis process. The simplest is the empirical model, which employs global kinetics, where the Arrhenius expression is used to correlate the rates of mass loss with temperature. The pyrolysis process of coal can be expressed by the following reaction:

$$
\text { Coal } \stackrel{k}{\longrightarrow} \text { Volatiles + Char }
$$

The general expression for the decomposition of a solid sample is

$$
\frac{d x}{d t}=k(T) f(x),
$$

where $x$ is the degree of conversion which represents the decomposed amount of the sample at time $t$ and is defined in terms of the change in mass of the sample:

$$
x=\frac{\left(m_{i}-m_{t}\right)}{\left(m_{i}-m_{f}\right)},
$$

where $m_{i}$ is the initial mass, $m_{f}$ is the final mass, and $m_{t}$ is the mass at time $t$ of the sample analyzed by TGA; $f(x)$ is a function of $x$ depending on the reaction mechanism; $k(T)$ is the rate constant at temperature $T$, which generally obeys the Arrhenius equation:

$$
k(T)=A \exp \left(\frac{-E_{a}}{R T}\right),
$$

where $A$ is the preexponential factor $\left(\mathrm{min}^{-1}\right)$. Equation is the activation energy $\left(\mathrm{kJ} \mathrm{mol}^{-1}\right), R$ is the universal gas constant $\left(\mathrm{J} \mathrm{K}^{-1} \mathrm{~mol}^{-1}\right)$, and $T$ is the absolute temperature $(\mathrm{K})$.

Substitution of (5) into (3) gives the general expression to calculate the kinetic parameters:

$$
\frac{d x}{d t}=f(x) A \exp \left(\frac{-E_{a}}{R T}\right) .
$$


There are various possibilities to express the conversion function $f(x)$ for the solid-state reactions. Most of the previous authors used the conversion function as follows:

$$
f(x)=(1-x)^{n},
$$

where $n$ is the reaction order; here it is considered first order. Combining (6) and (7), the kinetic equation of decomposition is obtained as follows:

$$
\frac{d x}{d t}=A \exp \left(\frac{-E_{a}}{R T}\right)(1-x)^{n} .
$$

Under nonisothermal conditions in which samples are heated at constant heating rates, the actual temperature under this condition can be expressed as

$$
T=T_{0}+\beta t
$$

where $T_{0}$ is the initial temperature, $\beta$ is the linear heating rate $\left({ }^{\circ} \mathrm{C} / \mathrm{min}\right)$, and $T$ is the temperature at time $t$. Nonisothermal methods are usually common in solid-state kinetics because they require less experimental data in comparison to isothermal methods. The following expression can be considered for nonisothermal experiments:

$$
\frac{d x}{d T}=\frac{d x}{d t} \cdot \frac{d t}{d T}
$$

where $d x / d T$ is the nonisothermal reaction rate, $d x / d t$ is the isothermal reaction rate, and $d T / d t$ is the heating rate $(\beta)$. Substituting (8) into (10) gives

$$
\frac{d x}{d T}=\frac{A}{B} \exp \left(\frac{-E_{a}}{R T}\right)(1-x)^{n} .
$$

Equation (11) represents the differential form of the nonisothermal rate law. In this study the data from nonisothermal experiments are considered to calculate kinetic parameters based on model-free methods such as Kissinger and the isoconversional methods of Ozawa, Kissinger-Akahira-Sunose, and Friedman and compared in order to analyze and to investigate thermal behavior of a Canadian lignite coal.

2.4. Model-Free Methods. The kinetic analysis based on model-free methods allows the kinetic parameters to be evaluated for different constant extents of conversion without evaluating any particular form of the reaction model. The temperature sensitivity of the reaction rate depends on the extent of conversion to products. This is partly a result of the heterogeneous nature of solid-state reactions such as coal pyrolysis; it also arises somewhat because many solid-state reactions follow complex mechanisms including multiple series and parallel stages with different activation energies. Model-fitting methods are applied to extract a single set of Arrhenius parameters for an overall process and are not capable to show this type of complexity in the solid-state reactions. Model-free methods are able of addressing the aforementioned drawbacks of the model-fitting methods. The ability of model-free methods to show this type of reaction complexity is therefore a critical step toward the ability to explain mechanistic conclusions from kinetic data.
2.4.1. Kissinger Method. According to Kissinger, the maximum reaction rate occurs with an increase in the reaction temperature [27]. The degree of conversion at the peak temperature of the DTG curve is a constant at different heating rates. Kissinger method is a model-free method, but it is not isoconversional method because it assumes constant activation energy with the progress of conversion. In Kissinger equation (12), $T_{m}$, representing the peak temperature, is expressed as

$$
\ln \left(\frac{B}{T_{m}^{2}}\right)=\ln \left(\frac{A R}{E_{a}}\right)-\frac{E_{a}}{R T_{m}} .
$$

Therefore, kinetic parameters including activation energy $\left(E_{a}\right)$ and preexponential factor $(A)$ can be obtained from a plot of $\ln \left(B / T_{m}^{2}\right)$ versus $1000 / T_{m}$ for a series of experiments at different heating rates.

2.4.2. Kissinger-Akahira-Sunose (KAS) Method. The KissingerAkahira-Sunose (KAS) method was based on the following equation:

$$
\ln \left(\frac{B}{T^{2}}\right)=\ln \left(\frac{A R}{E_{a} g(x)}\right)-\frac{E_{a}}{R T},
$$

where $g(x)$ is the integral conversion function (reaction model) which is reported in the literature [15]. For constant conversion a plot of left side of the above equation against $1000 / T$ at different heating rates is a straight line whose slope and intercept can evaluate the activation energy and preexponential factor, respectively.

2.4.3. The Flynn-Wall-Ozawa (FWO) Method. The KissingerAkahira-Sunose (FWO) method is based on the following equation:

$$
\ln (B)=\ln \left(\frac{A E_{a}}{R g(x)}\right)-5.331-1.052 \frac{E_{a}}{R T} .
$$

Thus, for a constant conversion, a plot of natural logarithm of heating rates, $\ln (B)$, versus $1000 / T$ obtained from thermal curves recorded at different heating rates will be a straight line whose slope $\left(-1.052\left(E_{a} / R T\right)\right)$ will calculate the activation energy.

2.4.4. Friedman Method. This method is one of the first isoconversional methods. Using (2) and (4) and taking the natural logarithm of each side, the expression proposed by Friedman can be presented as

$$
\ln \left(\frac{d x}{d t}\right)=\ln [A f(x)]-\frac{E_{a}}{R T} .
$$

The activation energy $\left(E_{a}\right)$ is determined from the slope of the plot of $\ln (d x / d t)$ versus $1000 / T$ at a constant conversion value. 


\section{Results and Discussion}

3.1. Thermal Decomposition Process. The TG and DTG curves of the pyrolysis of a Canadian lignite coal under nitrogen atmosphere obtained at six different heating rates of $1,6,9,12$, 15 , and $18 \mathrm{~K} \mathrm{~min}^{-1}$ are shown in Figures 1 and 2, respectively. The TG curves show the percentage mass loss of a coal sample over the range of temperature from $298 \mathrm{~K}$ to $1173 \mathrm{~K}$. The rate of mass loss is temperature dependent: the higher the temperature, the larger the mass loss because pyrolysis process proceeds slowly at low temperatures. As shown in Figure 1, the devolatilization process launches at temperature about $450 \mathrm{~K}$ and proceeds fast with elevating the temperature up to $850 \mathrm{~K}$ and then the mass loss of the sample drops slowly to the ultimate temperature. The DTG curves of sample at different heating rates are illustrated in Figure 2. The DTG curve exhibits three zones related to moisture evaporation, primary decomposition, and secondary decomposition. The first zone represents elimination of moisture which occurs below $450 \mathrm{~K}$ [28]. The second region is related to main decomposition stage in the temperature range $450-850 \mathrm{~K}$ for low heating rate and $925 \mathrm{~K}$ for high heating rate. Major volatile matter at this stage liberated from coal structure that was formed by thermal decomposition some covalent bond such as ether bonds and methylene group which will form gases such as hydrogen, carbon monoxide, and lighter hydrocarbons [29]. This region is the most significant region to examine since the major weight loss and complicated chemical reaction, such as release of tar and gaseous products and semicoke formation, take place in this temperature range $[30,31]$. The third zone, that is, the second pyrolysis stage, where low decomposition rates are observed can be attributed to the further gasification of the formed char due to high temperature effects. On the other hand, the coal sample contains high ash and the phase transitions of the inorganics found in the mineral matter, losses of the molecular water contents of the clay minerals, and decomposition of carbonate minerals may contribute to weight loss of this step. There is only a small drop of mass observed at this stage. The TGA data are normalized from 0 to 1 before analysis. The temperature at which the derivative of mass loss starts to increase is selected as the zero conversion point, and the temperature at which the mass derivative returned to the base line is chosen as end point. It is known that the heating rate affects all TGA curves and the maximum decomposition rate. When heating rate increases, the temperature of the maximum decomposition rate of the coal shifted toward higher temperature. Figure 3 shows conversion curves versus temperature at different heating rates. The curves showed typical sigmoid shape of kinetic curves. With increasing the heating rate, conversion values reached higher temperatures because at the same temperature and time a high heating rate has a short decomposition time and the temperature required for the sample to reach the same conversion will be higher. The heat transfer limitation (thermal lag) exists between furnace and sample temperature. It means that temperature in the particle can be a little lower than furnace temperature and gradient of temperature may exist in the coal sample, so in order to reduce the thermal lag, the coal sample should be ground to the fine particle to

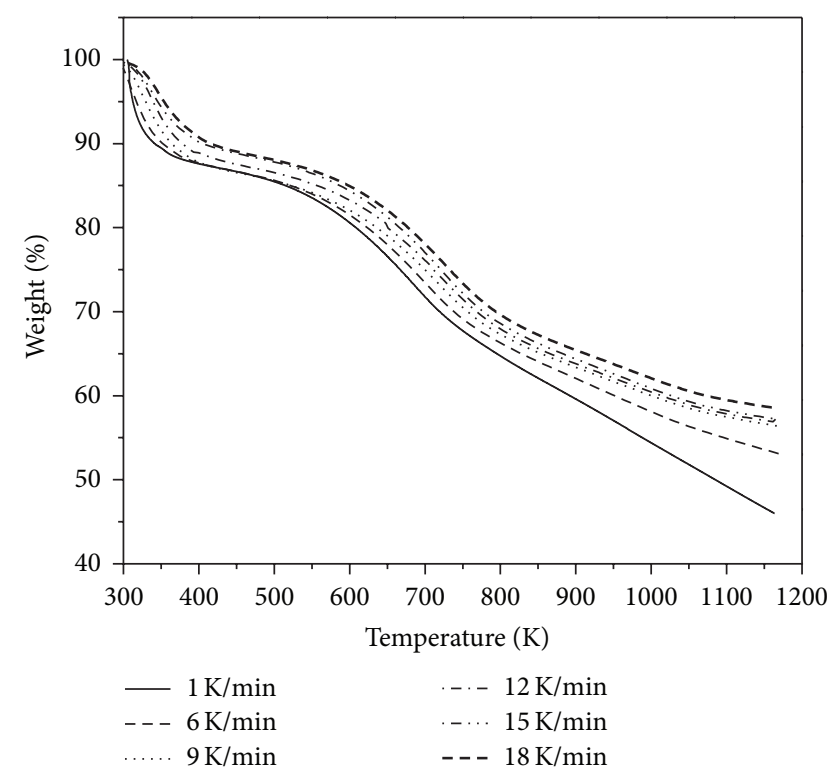

FIGURE 1: Thermal behavior of Poplar coal at different heating rates under $\mathrm{N}_{2}$ atmosphere.

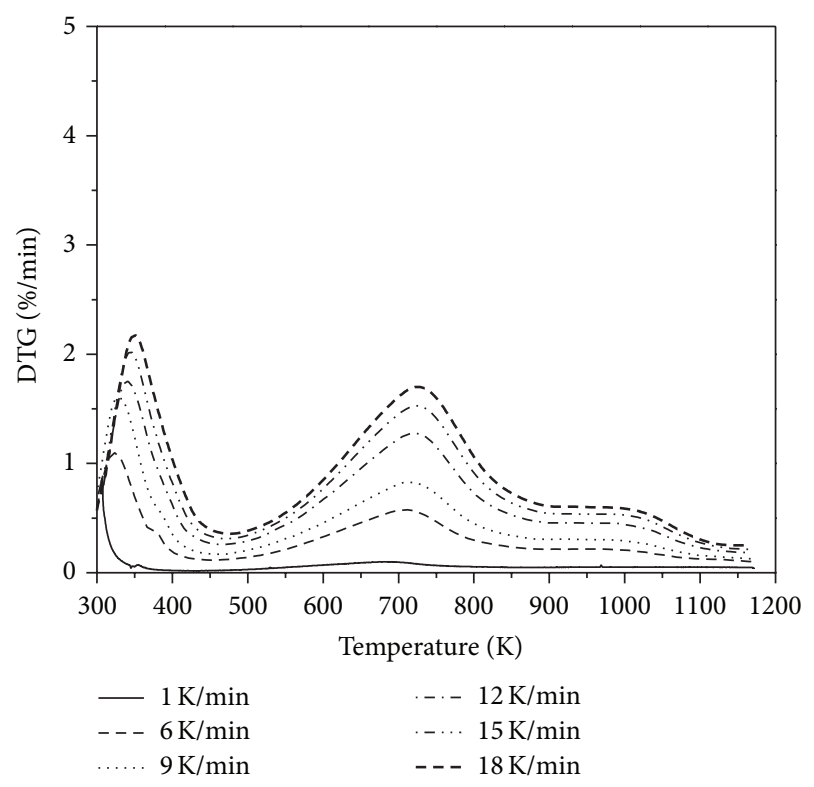

FIGURE 2: DTG curves of Poplar coal at different heating rates under $\mathrm{N}_{2}$ atmosphere.

increase the surface area of particle and consequently increase the heat transfer effect between the sample surface and the crucible as large as possible.

3.2. Kinetic Analysis. The results of TG/DTG experimental data of coal pyrolysis obtained under nonisothermal condition under nitrogen atmosphere were used for kinetic analysis. Different model-free methods such as Kissinger and the isoconversional methods of Ozawa, Kissinger-AkahiraSunose, and Friedman are employed in order to obtain parameters like the activation energy and preexponential 


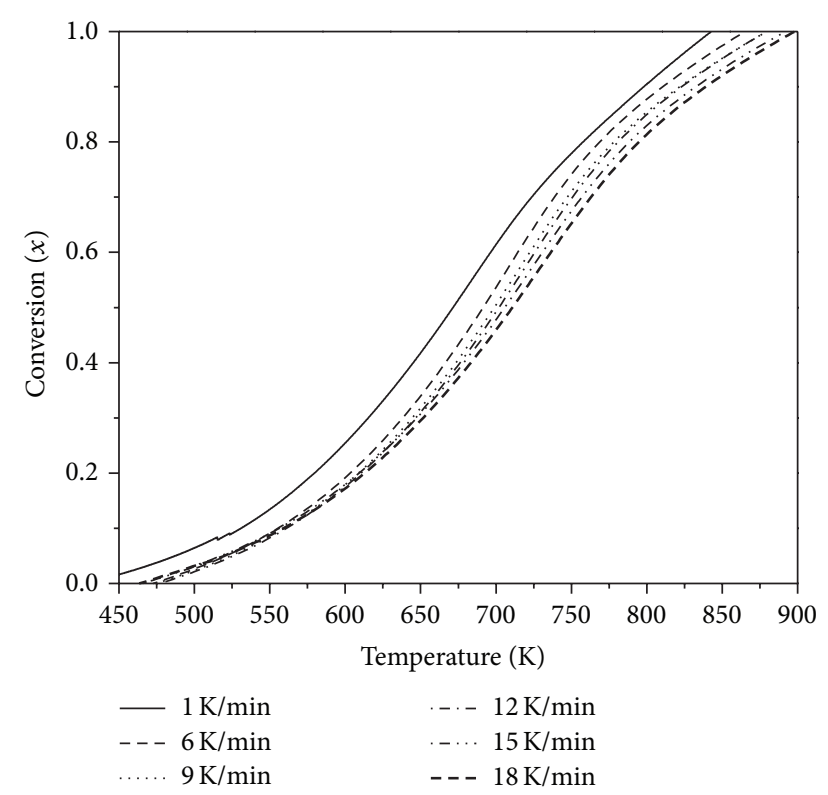

FIGURE 3: Conversion curves for different heating rates for pyrolysis of lignite coal under $\mathrm{N}_{2}$ atmosphere.

factor. In the Kissinger method the degree of conversion at the peak temperature $\left(T_{m}\right)$ is a constant under different heating rates. The kinetic parameters using Kissinger method were found by linear regression line which is shown in Figure 4. The activation energy and preexponential factor extracted from the slope and intercept are $281 \mathrm{~kJ} \mathrm{~mol}^{-1}$ and $2.61 \times$ $10^{17} \mathrm{~min}^{-1}$, respectively. The activation energy and preexponential factor were calculated as a function of conversion by using isoconversional methods of KAS, FWO, and Friedman methods. The isoconversional plots of these methods are shown in Figures 5-7, respectively. Different range of conversion from 0.05 to 0.9 is considered for calculating the kinetic parameters based on isoconversional method. The activation energies from the slope and preexponential factors from the intercept of three different isoconversional methods were obtained and listed in Table 2 . It can be observed from Table 2 that the values of activation energies are not similar at different constant extents of conversion because most solidstate reactions are not simple one-step mechanism and follow a complex multistep reaction. The thermogravimetric data analysis by isoconversional technique may reveal complexity of the solid-state reactions such as coal pyrolysis [14]. It means that in the pyrolysis process of coal the activation energy is a function of conversion. Figure 8 shows the dependence of the activation energy on extent of conversion. The activation energy rises from about $130 \mathrm{~kJ} \mathrm{~mol}^{-1}$ at low conversion to nearly $350 \mathrm{~kJ} \mathrm{~mol}^{-1}$ at $75 \%$ conversion, and it subsequently drops to about $300 \mathrm{~kJ} \mathrm{~mol}^{-1}$ near the end of reaction. The initial activation energy value was low due to cleavage of some weak bonds and elimination of volatile components from the coal matrix because at the beginning of the process all the strong bonds are not cleaved. Therefore, more activation energy is required to decompose these stable molecules. With the progress of pyrolysis process the value of activation

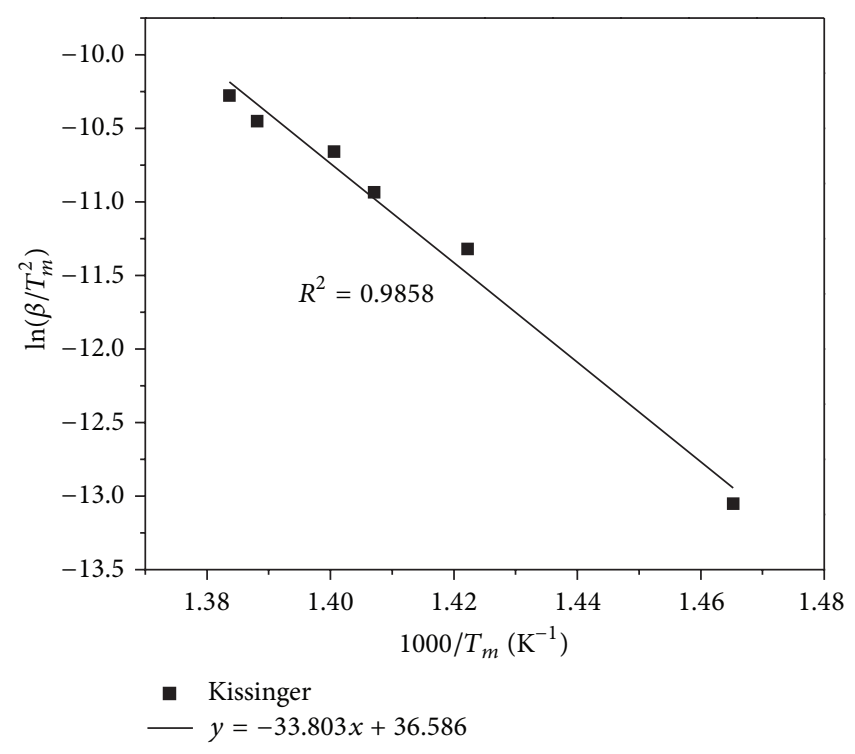

FIGURE 4: Kissinger plot of lignite coal pyrolysis at different heating rates.

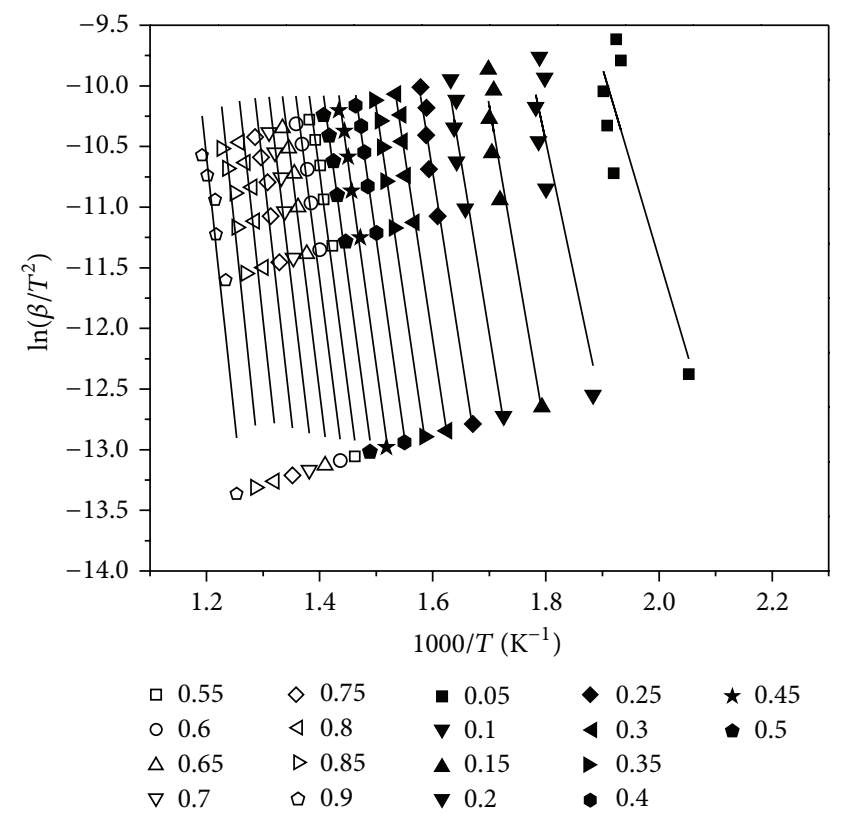

FIGURE 5: KAS plots of lignite coal pyrolysis at different values of conversion.

energy increased up to conversion of $75 \%$ with breaking of some strong covalent linkages. For higher conversion values above $75 \%$ the activation energy gradually decreases. The reason arises from the fact that during the decomposition process at high temperature with high conversion when most of the stable bonds are broken, less stable molecules which are easier to break are present, so less energy barrier is required for decomposition at this step and the value of activation energy decreases with progress of conversion. The arithmetic means of the activation energy calculated by KAS, FWO, and Friedman method are 282,275 , and $283 \mathrm{~kJ} \mathrm{~mol}^{-1}$, respectively, 


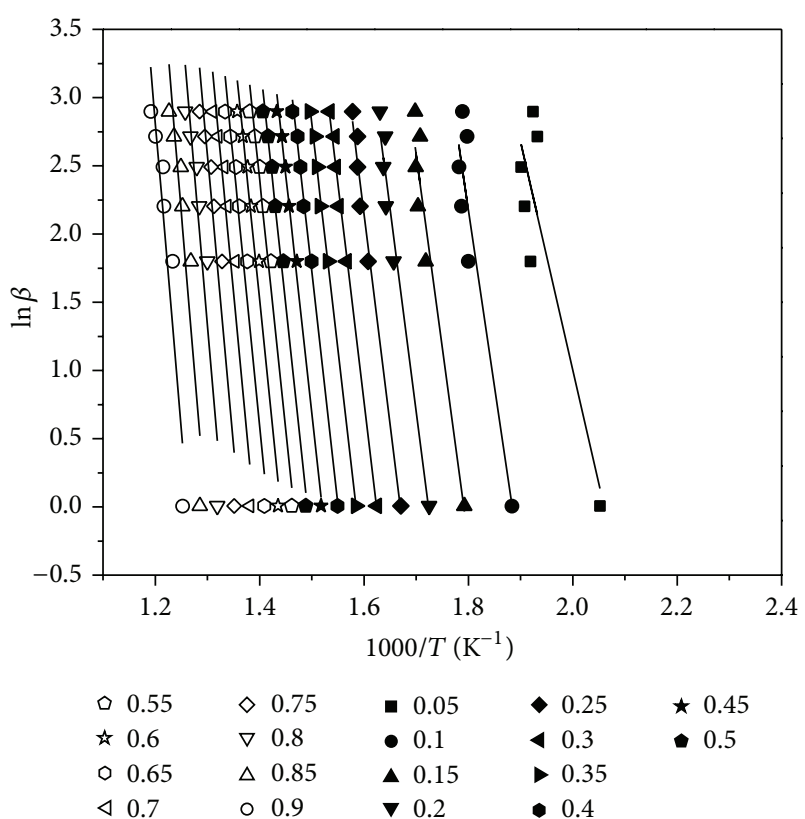

FIGURE 6: FWO plots of lignite coal pyrolysis at different values of conversion.

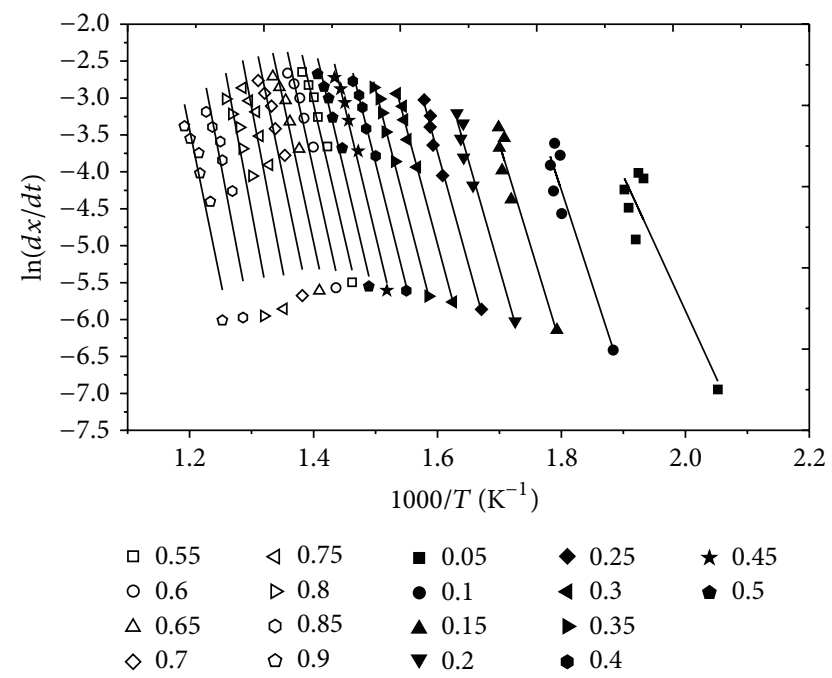

FIGURE 7: Friedman plots of lignite coal pyrolysis at different values of conversion.

which are close to average activation energy obtained from the Kissinger method $\left(281.03 \mathrm{~kJ} \mathrm{~mol}^{-1}\right)$. The results obtained with KAS and Friedman methods are very close and in good agreement [32]. The kinetic data obtained for pyrolysis of coal are found to agree closely with some of the literature data. However, the differences observed in the literature data can be attributed to the fact that the pyrolysis characteristics of coal highly depend on the properties of the coal which in turn differs based on origin of the coal $[28,30,31]$.

The KAS and FWO methods were originally derived with constant activation energies, so the errors associated with kinetic measurements from methods should be dependent

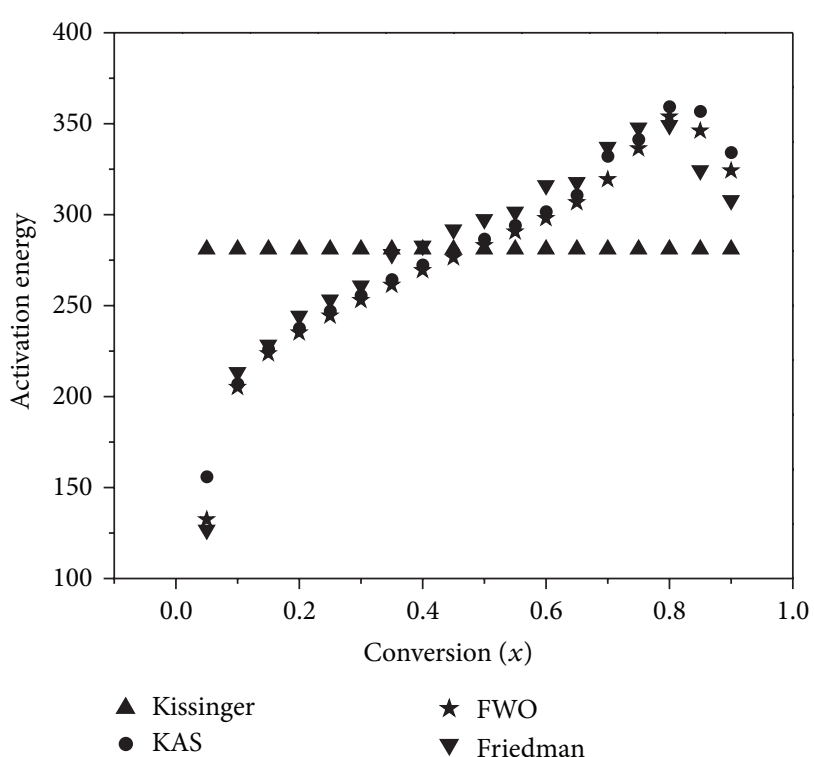

FIGURE 8: The activation energy as a function of conversion using model-free isoconversional technique.

on the variation of the activation energy with respect to conversion. This error does not appear in the Friedman method [33, 34]. Another advantage that can be attributed to Friedman method is that the activation energies obtained by the Friedman method are independent of the range of heating rates which can decrease the systematic error in evaluating the activation energy values. Thus, Friedman method can be considered to be the best among the four model-free methods in order to evaluate kinetic parameters for solidstate reactions [33, 34]. The kinetic parameters obtained in this study can be useful for pyrolysis and gasification researchers to predict kinetic model of coal pyrolysis and optimization of the process conditions.

\section{Conclusion}

In this study, the pyrolysis kinetics of a Canadian lignite coal was carried out by means of thermogravimetric analysis (TG) in the temperature range of $298-1173 \mathrm{~K}$ at six different heating rates of $1,6,9,12,15$, and $18 \mathrm{~K} \mathrm{~min}^{-1}$ under nitrogen atmosphere. It was found that the main pyrolysis process occurred in the temperature range $450-850 \mathrm{~K}$. In this work kinetic study and thermal behavior of lignite coal were presented where Arrhenius parameters were determined and compared through four different methods of Kissinger, Ozawa, KAS, and Friedman. The activation energy is calculated as a function of conversion by using these methods and is found to be similar. Among these methods, Friedman method was considered to be the best in order to evaluate kinetic parameters for solid-state reactions such as coal pyrolysis. Methods such as FWO and KAS are restricted to the use of a linear variation of the temperature and positive heating rate. Moreover, they are generated based on mathematical approximation which can enhance systematic error. The advantage 
TABLE 2: Calculated kinetic parameters for a Canadian lignite coal by three different isoconversional methods.

\begin{tabular}{|c|c|c|c|c|c|c|}
\hline \multirow{2}{*}{$x$} & \multicolumn{2}{|c|}{ Friedman } & \multicolumn{2}{|c|}{ KAS } & \multicolumn{2}{|c|}{ FWO } \\
\hline & $E_{a}\left(\mathrm{~kJ} \mathrm{~mol}^{-1}\right)$ & $A\left(\min ^{-1}\right)$ & $E_{a}\left(\mathrm{~kJ} \mathrm{~mol}^{-1}\right)$ & $A\left(\min ^{-1}\right)$ & $E_{a}\left(\mathrm{~kJ} \mathrm{~mol}^{-1}\right)$ & $A\left(\min ^{-1}\right)$ \\
\hline 0.05 & 126.65 & $2.02 \cdot 10^{13}$ & 155.76 & $4.86 \cdot 10^{08}$ & 132.33 & $1.00 \cdot 10^{15}$ \\
\hline 0.1 & 213.44 & $1.85 \cdot 10^{18}$ & 206.81 & $2.10 \cdot 10^{15}$ & 205.19 & $1.95 \cdot 10^{21}$ \\
\hline 0.15 & 228.44 & $6.06 \cdot 10^{18}$ & 225.84 & $1.92 \cdot 10^{16}$ & 223.71 & $1.24 \cdot 10^{22}$ \\
\hline 0.2 & 244.33 & $3.06 \cdot 10^{19}$ & 237.45 & $4.52 \cdot 10^{16}$ & 235.11 & $2.32 \cdot 10^{22}$ \\
\hline 0.25 & 253.26 & $4.70 \cdot 10^{19}$ & 246.90 & $8.12 \cdot 10^{16}$ & 244.40 & $3.54 \cdot 10^{22}$ \\
\hline 0.3 & 261.02 & $6.45 \cdot 10^{19}$ & 255.55 & $1.39 \cdot 10^{17}$ & 252.90 & $5.36 \cdot 10^{22}$ \\
\hline 0.35 & 278.20 & $1.44 \cdot 10^{20}$ & 264.15 & $2.57 \cdot 10^{17}$ & 261.32 & $8.97 \cdot 10^{22}$ \\
\hline 0.4 & 282.82 & $2.16 \cdot 10^{20}$ & 272.26 & $4.58 \cdot 10^{17}$ & 269.26 & $1.48 \cdot 10^{23}$ \\
\hline 0.45 & 291.70 & $1.01 \cdot 10^{21}$ & 279.46 & $7.16 \cdot 10^{17}$ & 276.32 & $2.19 \cdot 10^{23}$ \\
\hline 0.5 & 297.47 & $1.23 \cdot 10^{21}$ & 286.39 & $1.10 \cdot 10^{18}$ & 283.13 & $3.26 \cdot 10^{23}$ \\
\hline 0.55 & 309.85 & $1.15 \cdot 10^{21}$ & 302.26 & $1.93 \cdot 10^{18}$ & 290.51 & $5.56 \cdot 10^{23}$ \\
\hline 0.6 & 316.12 & $6.15 \cdot 10^{21}$ & 301.49 & $3.36 \cdot 10^{18}$ & 297.88 & $9.56 \cdot 10^{23}$ \\
\hline 0.65 & 326.06 & $9.62 \cdot 10^{21}$ & 318.88 & $7.25 \cdot 10^{18}$ & 306.72 & $2.07 \cdot 10^{24}$ \\
\hline 0.7 & 337.07 & $3.47 \cdot 10^{22}$ & 332.03 & $2.88 \cdot 10^{19}$ & 319.43 & $1.64 \cdot 10^{26}$ \\
\hline 0.75 & 347.83 & $1.13 \cdot 10^{24}$ & 341.26 & $1.93 \cdot 10^{20}$ & 336.36 & $5.76 \cdot 10^{25}$ \\
\hline 0.8 & 349.20 & $1.36 \cdot 10^{24}$ & 359.30 & $1.15 \cdot 10^{21}$ & 353.79 & $3.67 \cdot 10^{26}$ \\
\hline 0.85 & 324.31 & $1.07 \cdot 10^{23}$ & 356.75 & $1.12 \cdot 10^{21}$ & 346.15 & $4.30 \cdot 10^{26}$ \\
\hline 0.9 & 307.81 & $8.36 \cdot 10^{20}$ & 334.15 & $9.43 \cdot 10^{19}$ & 324.22 & $5.04 \cdot 10^{25}$ \\
\hline
\end{tabular}

of the Friedman method is that it is free of mathematical approximations and is not restricted to the use of a linear variation of the heating rate. Experimental results showed that values of kinetic parameters were almost the same and in good agreement. The isoconversional technique gives comparably reliable predictions of reaction rates compared to the more traditional model-fitting. There is very little information regarding pyrolysis of coal itself based on modelfree methods. The results can provide useful information for pyrolysis researchers in order to predict kinetic model of coal pyrolysis and optimization of the process conditions.

\section{Conflict of Interests}

The authors declare that there is no conflict of interests regarding the publication of this paper.

\section{References}

[1] M. Balat, "Coal in the global energy scene," Energy Sources, Part B: Economics, Planning and Policy, vol. 5, no. 1, pp. 50-62, 2009.

[2] T. Kabe, A. Ishihara, W. Qian, I. P. Sutrisna, and Y. Kabe, Coal and Coal-Related Compounds: Structures, Reactivity and Catalytic Reactions, Elsevier, New York, NY, USA, 2004.

[3] S. Vasireddy, B. Morreale, A. Cugini, C. Song, and J. J. Spivey, "Clean liquid fuels from direct coal liquefaction: chemistry, catalysis, technological status and challenges," Energy and Environmental Science, vol. 4, no. 2, pp. 311-345, 2011.

[4] M. R. Khan, Advances in Clean Hydrocarbon Fuel Processing: Science and Technology, Woodhead Pubishing Series in Energy, 2011.

[5] M. Brown, Introduction to Thermal Analysis: Techniques and Applications, Springer, 2001.
[6] M. Höök and K. Aleklett, "A review on coal-to-liquid fuels and its coal consumption," International Journal of Energy Research, vol. 34, no. 10, pp. 848-864, 2010.

[7] N. Punsuwan and C. Tangsathitkulchai, "Product characterization and kinetics of biomass pyrolysis in a three-zone freefall reactor," International Journal of Chemical Engineering, vol. 2014, Article ID 986719, 10 pages, 2014.

[8] M. Varol, A. T. Atimtay, B. Bay, and H. Olgun, "Investigation of co-combustion characteristics of low quality lignite coals and biomass with thermogravimetric analysis," Thermochimica Acta, vol. 510, no. 1-2, pp. 195-201, 2010.

[9] HC. Howard, Chemistry of Coal Utilization. Second Supplementary Volume, John Wiley, New York, NY, USA, 1963.

[10] G. J. Lawson, Differential Thermal Analysis, Fundamental Aspects, Academic Press, New York, NY, USA, 1970.

[11] D. B. Anthony and J. B. Howard, "Coal devolatilization and hydrogastification," AIChE Journal, vol. 22, no. 4, pp. 625-656, 1976.

[12] V. V. Hathi, Thermal and kinetic analysis of the pyrolysis of coals [Ph.D. thesis], University of Oklahoma, Norman, Okla, USA, 1978.

[13] A. Khawam, Application of solid-state kinetics to desolvation reactions [Ph.D. thesis], University of Iowa, Iowa City, Iowa, USA, 2007.

[14] S. Scaccia, "TG-FTIR and kinetics of devolatilization of Sulcis coal," Journal of Analytical and Applied Pyrolysis, vol. 104, pp. 95-102, 2013.

[15] S. S. Idris, N. A. Rahman, K. Ismail, A. B. Alias, Z. A. Rashid, and M. J. Aris, "Investigation on thermochemical behaviour of low rank Malaysian coal, oil palm biomass and their blends during pyrolysis via thermogravimetric analysis (TGA)," Bioresource Technology, vol. 101, no. 12, pp. 4584-4592, 2010. 
[16] G. Jiang, D. J. Nowakowski, and A. V. Bridgwater, "A systematic study of the kinetics of lignin pyrolysis," Thermochimica Acta, vol. 498, no. 1-2, pp. 61-66, 2010.

[17] N. Sbirrazzuoli, L. Vincent, A. Mija, and N. Guigo, "Integral, differential and advanced isoconversional methods: complex mechanisms and isothermal predicted conversion-time curves," Chemometrics and Intelligent Laboratory Systems, vol. 96, no. 2, pp. 219-226, 2009.

[18] J. Zsakó, "Kinetic analysis of thermogravimetric data," The Journal of Physical Chemistry, vol. 72, no. 7, pp. 2406-2411, 1968.

[19] K. Miura, "New and simple method to estimate $\mathrm{f}(\mathrm{E})$ and $\mathrm{k0}(\mathrm{E})$ in the distributed activation energy model from three sets of experimental data," Energy and Fuels, vol. 9, no. 2, pp. 302-307, 1995.

[20] A. O. Aboyade, M. Carrier, E. L. Meyer, J. H. Knoetze, and J. F. Görgens, "Model fitting kinetic analysis and characterisation of the devolatilization of coal blends with corn and sugarcane residues," Thermochimica Acta, vol. 530, pp. 95-106, 2012.

[21] S.-L. Niu, K.-H. Han, and C.-M. Lu, "Characteristic of coal combustion in oxygen/carbon dioxide atmosphere and nitric oxide release during this process," Energy Conversion and Management, vol. 52, no. 1, pp. 532-537, 2011.

[22] H. B. Vuthaluru, "Investigations into the pyrolytic behaviour of coal/biomass blends using thermogravimetric analysis," Bioresource Technology, vol. 92, no. 2, pp. 187-195, 2004.

[23] C. A. Ulloa, A. L. Gordon, and X. A. García, "Thermogravimetric study of interactions in the pyrolysis of blends of coal with radiata pine sawdust," Fuel Processing Technology, vol. 90, no. 4, pp. 583-590, 2009.

[24] H. Haykiri-Acma and S. Yaman, "Synergy in devolatilization characteristics of lignite and hazelnut shell during co-pyrolysis," Fuel, vol. 86, no. 3, pp. 373-380, 2007.

[25] M. Karthikeyan, W. Zhonghua, and A. S. Mujumdar, "Lowrank coal drying technologies-current status and new developments," Drying Technology, vol. 27, no. 3, pp. 403-415, 2009.

[26] S. A. Channiwala and P. P. Parikh, "A unified correlation for estimating HHV of solid, liquid and gaseous fuels," Fuel, vol. 81, no. 8, pp. 1051-1063, 2002.

[27] H. E. Kissinger, "Reaction kinetics in differential thermal analysis," Analytical Chemistry, vol. 29, no. 11, pp. 1702-1706, 1957.

[28] A. O. Aboyade, J. F. Görgens, M. Carrier, E. L. Meyer, and J. H. Knoetze, "Thermogravimetric study of the pyrolysis characteristics and kinetics of coal blends with corn and sugarcane residues," Fuel Processing Technology, vol. 106, pp. 310-320, 2013.

[29] Y. Güldoğan, T. Durusoy, and T. Bozdemir, "Effects of heating rate and particle size on pyrolysis kinetics of gediz lignite," Energy Sources, vol. 24, no. 8, pp. 753-760, 2002.

[30] S. Sharma and A. K. Ghoshal, "Study of kinetics of co-pyrolysis of coal and waste LDPE blends under argon atmosphere," Fuel, vol. 89, no. 12, pp. 3943-3951, 2010.

[31] M. Güneş and S. K. Güneş, "Distributed activation energy model parameters of some Turkish coals," Energy Sources, Part A: Recovery, Utilization and Environmental Effects, vol. 30, no. 16, pp. 1460-1472, 2008

[32] L. Gašparovič, Z. Koreňová, and L'. Jelemenský, "Kinetic study of wood chips decomposition by TGA," Chemical Papers, vol. 64, no. 2, pp. 174-181, 2010.
[33] S. Vyazovkin and N. Sbirrazzuoli, "Isoconversional kinetic analysis of thermally stimulated processes in polymers," Macromolecular Rapid Communications, vol. 27, no. 18, pp. 1515-1532, 2006.

[34] W. Wu, J. Cai, and R. Liu, "Isoconversional kinetic analysis of distributed activation energy model processes for pyrolysis of solid fuels," Industrial and Engineering Chemistry Research, vol. 52, no. 40, pp. 14376-14383, 2013. 

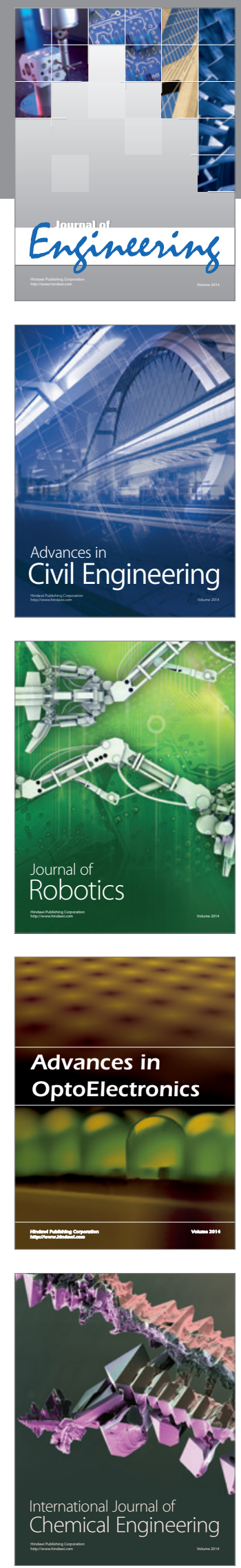

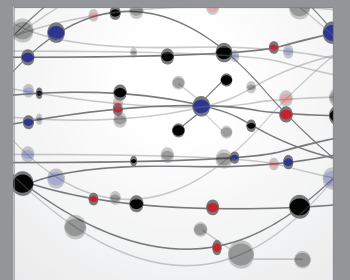

The Scientific World Journal
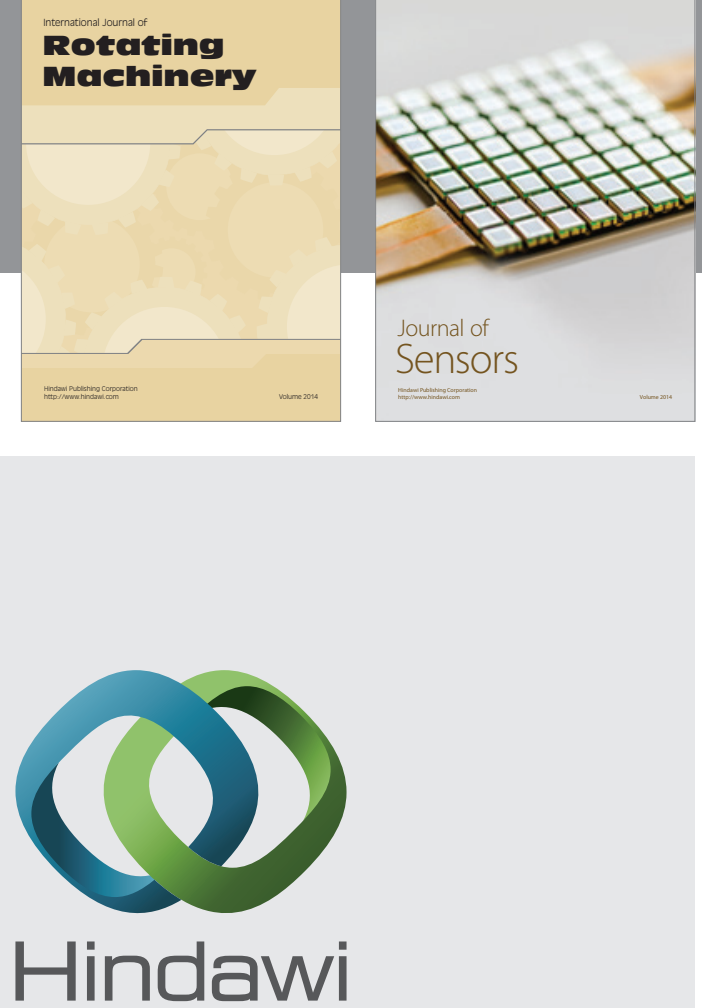

Submit your manuscripts at http://www.hindawi.com
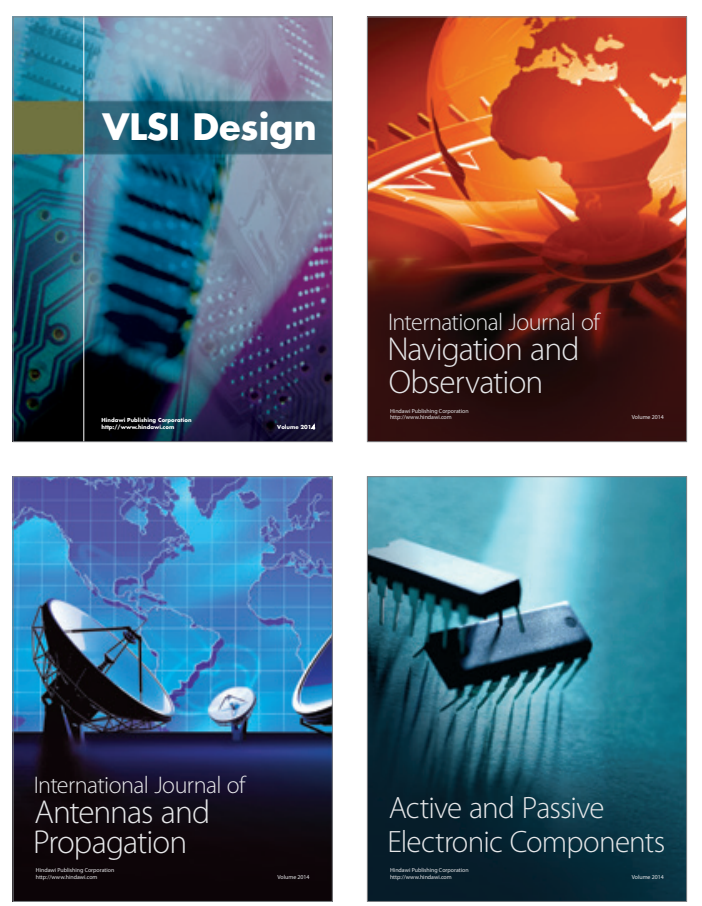
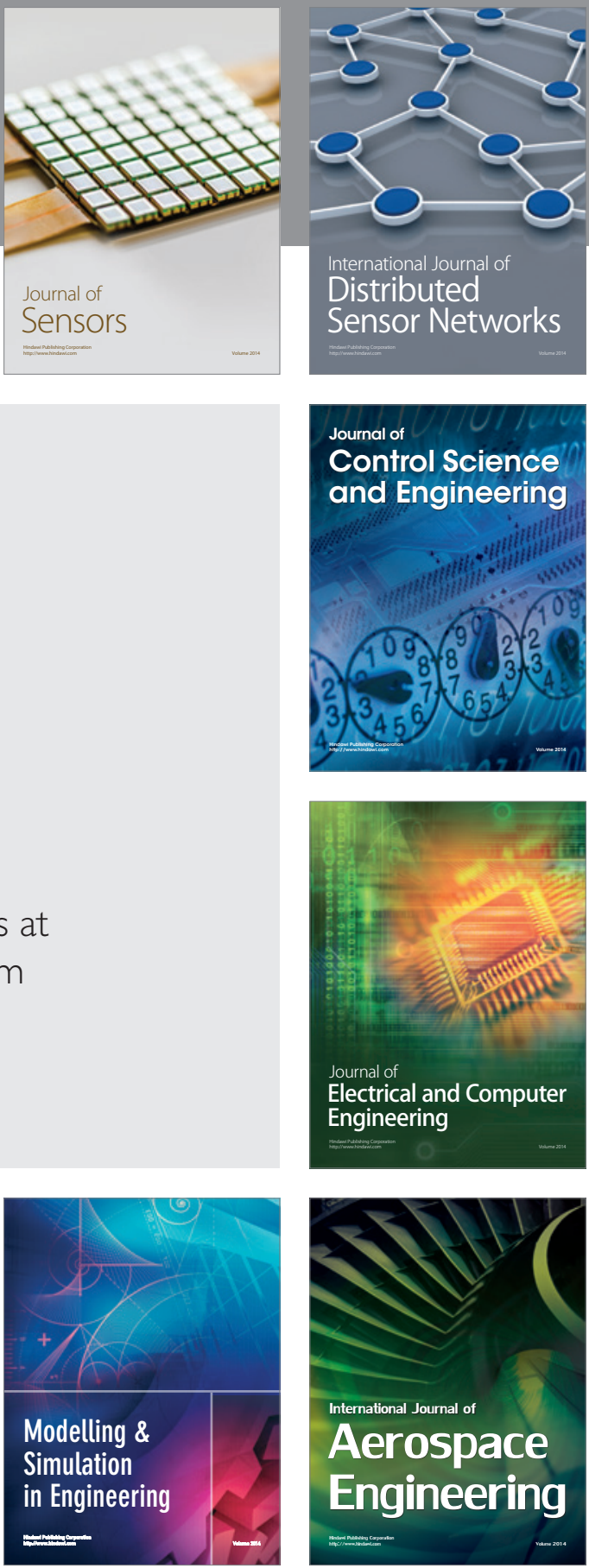

Journal of

Control Science

and Engineering
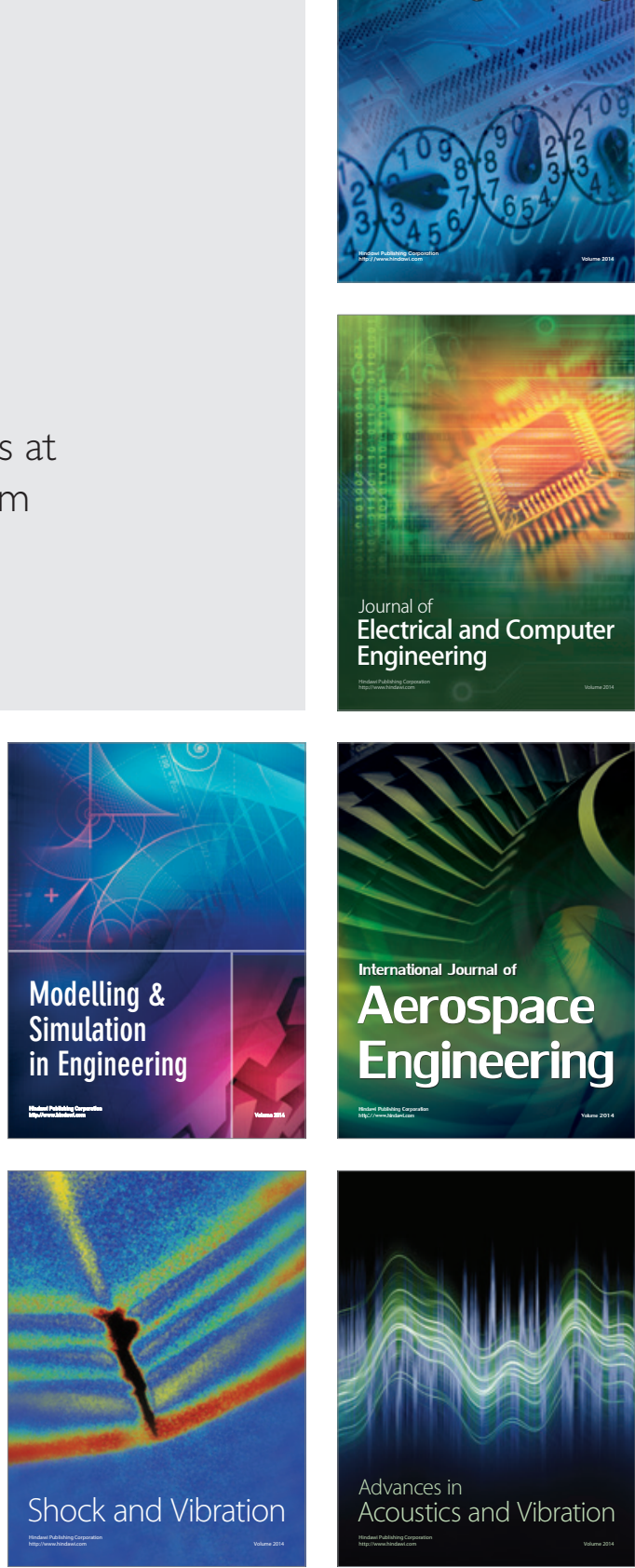